\title{
PENGEMBANGAN BUKU LATIHAN SIKLUS AKUNTANSI PERUSAHAAN DAGANG (BLSAPD) PADA MATA KULIAH PENGANTAR AKUNTANSI 1 PROGRAM STUDI PENDIDIKAN AKUNTANSI UNIVERSITAS ISLAM RIAU
}

\author{
(Development Of Trading Company Accounting Cycle Training Book (BLSAPD) in \\ Introduction To Accounting 1 Course For Accounting Education Department \\ at Riau Islamic University)
}

\author{
Akhmad Suyono *) \\ Email: $\underline{\text { Akhmad@edu.uir.ac.id }}$
}

*) Fakultas Keguruan Dan Ilmu Pendidikan, Universitas Islam Riau

Jl. Kaharuddin Nasution No. 113 Perhentian Marpoyan, Pekanbaru - Riau. 28284

\begin{abstract}
Based on preliminary observations on accounting education students in semester 1, accounting learning problems that arise include; (1) motivation to learn independently decreases because the contents, language, and pictures of textbooks are not interesting, (2) motivation to do independent assignments is also reduced due to the unavailability of applicative media for accounting exercises, and (3) subject lecturers are still having trouble finding, concocting and linking one material with another, because the practice questions are only limited to the material in the package book. This study uses a teaching material development model suggested by Thiagarajan, Semmel \& Semmel (1974: 5-9) is a 4-D model. This model consists of four stages of development, namely define, design, develop and disseminate. Data collection techniques use interviews, questionnaires and documentation. The instrument test uses expert validity test, individual test and small group test, the data analysis technique uses qualitative and descriptive data analysis. Because this research is a development, the results in this study are teaching material products. The prototype draft is (1) BLSAPD for students (2) BLSAPD guidelines for lecturers' guidance. Based on the recapitulation of small group test results against BPSAPD, for the display aspect expressed in percentage of $78.06 \%$ so that this book was declared very interesting for students, for the language aspect stated in a percentage of $87.37 \%$ so that this book was declared very easily understood by students, while for the material content aspect is stated as a percentage of $89.65 \%$ and this book is stated in the very clear category. So the percentage of small group test results as a whole is $78.06 \%+87.37 \%+89.65 \% / 3=$ $84.66 \%$. With reference to the eligibility criteria for product development, it can be said that the results of small group tests are qualified in valid and practical criteria.
\end{abstract}

Keywords: Exercise Book, Accounting Cycles and Trading Companies

\section{PENDAHULUAN}

Hingga saat ini pelajaran akuntansi bagi mahasiswa jurusan Pendidikan Akuntansi, masih menganggap pelajaran akuntansi merupakan mata pelajaran yang sulit untuk dipahami, hal ini disebabkan oleh beberapa faktor, yaitu: (1) akuntansi bukan pelajaran hapalan semata tetapi membutuh nalar logika berpikir kritis terhadap pristiwa transaksi ekonomi, sehingga dibutuhkan latihan-latihan untuk memahaminya (2) ada kecendrungan belajar akuntansi "membosankan" karena belajar akuntansi identik dengan menghitung uang-uang fiktif (bukan uang sebenarnya/uang dalam angka-angka).

Berdasarkan observasi awal di pada mahasiswa pendidikan akuntansi pada semester 1, masalah pembelajaran 
akuntansi yang muncul antara lain; (1) motivasi untuk belajar mandiri berkurang karena, isi, bahasa, dan gambar dari buku teks tidak sesuai dengan konteks dalam kehidupan nyata, (2) motivasi mengerjakan tugas mandiri juga berkurang karena belum tersedianya media aplikatif untuk latihan akuntansi, dan (3) dosen mata pelajaran masih kesulitan mencari, meramu dan mengkaitkan materi yang satu dengan yang lain, karena latihan soal hanya terbatas pada materi yang ada di buku paket saja. (4). Kebanyakan input dari mahasiswa prodi pendidikan akuntansi berasal dari sma/ma yang notabennya untuk mata pelajaran akuntansi mendapatkan jam belajar yang sangat minim, sehingga mereka kurang mendalami dan menyukai apa yang mereka pelajari. Dengan menggunakan tahapan-tahapan yang ada dalam model pengembangan Four-D, maka harus ada produk aplikatif dalam bentuk prototipe Buku Latihan Siklus Akuntansi Perusahaan Dagang (BLSAPD) yang valid, praktis dan efektif sehingga dapat meningkatkan kualitas proses dan hasil belajar.

Secara umum setiap model terdiri dari empat tahap: (1) tahap pendefinisian (define), yaitu tahapan yang bertujuan untuk menentukan dan mendefinisikan kebutuhan pembelajaran; (2) tahap perencanaan (design), yaitu perancangan prototipe buku latihan siklus akuntansi perusahaan dagang; (3) tahap pengembangan (develop); yaitu tahap pengembangan prototipebuku latihan siklus akuntansi perusahaan dagang, (4) tahap penyebaran (disseminate), yaitu tahap penggunaan perangkat yang dikembangkan.

Pengembangan ini diharapkan menghasilkan prototipe Buku Latihan Siklus Akuntansi Perusahaan Dagang
(BLSAPD) model praktikum, dilengkapi seperangkat desain pembelajaran dengan mengikuti prosedur-prosedur model pengembangan four- $D$, yang valid, praktis dan efektif sehingga meningkatkan proses dan hasil belajar mahasiswa.

\section{METODOLOGI PENELITIAN Tempat dan Waktu Penelitian}

Penelitian ini akan dilaksanakan di program studi pendidikan akuntansi FKIP Universitas Islam Riau. Pada Mata Kuliah Pengantar Akuntansi 1 yang merupakan dasar untuk mempelajari Akuntansi pada tingkat lanjut.

\section{Metode Penelitian}

Model pengembangan yang digunakan dalam bahan ajar akuntansi perusahaan dagang ini, menggunakan model Thiagarajan, Semmel \& Semmel yang dikenal dengan Four-D models (Model 4-D). Alasan pemilihan model Thiagarajan, Semmel \& Semmel antara lain: (1) langkah-langkah dalam model ini, relatif lebih sederhana, hal ini memudahkan untuk melakukan proses pengembangan bahan ajar akuntansi model praktikum untuk materi siklus akuntansi perusahaan dagang, (2) dalam pengembangan bahan ajar fokus terhadap karakter mahasiswa yaitu kemampuan atau pengetahuan alami mahasiswa, dan (3) dalam penentuan efektifan bahan ajar lebih obyektif (Thiagarajan, 1974; 4).

Untuk menarik kesimpulan guna merevisi produk buku praktik yang dikembangkan, hasil persentase tersebut dirujuk dengan tabel kreteria kelayakan produk sebagai berikut: 
Tabel 1. Kriteria Kelayakan Produk Pengembangan

\begin{tabular}{|l|l|c|c|}
\hline Skor & \multicolumn{1}{|c|}{$\begin{array}{c}\text { Skala } \\
\text { penilaian }\end{array}$} & Kualifikasi & Keterangan \\
\hline 5 & $85-100 \%$ & $\begin{array}{c}\text { Sangat Valid/sangat baik/ sangat } \\
\text { menarik/sangat sesuai/sangat efektif. }\end{array}$ & Tidak perlu revisi \\
\hline 4 & $75-84 \%$ & Valid/baik/menarik/sesuai/efektif & Tidak perlu revisi \\
\hline 3 & $65-74 \%$ & $\begin{array}{c}\text { Cukup valid/ cukup baik/cukup } \\
\text { menarik/cukup sesuai/cukup efektif }\end{array}$ & Revisi sedikit \\
\hline 2 & $45-64 \%$ & $\begin{array}{c}\text { Kurang Valid/kurang baik/kurang } \\
\text { menarik/kurang sesuai/kurang efektif }\end{array}$ & Revisi \\
\hline 1 & $0-44 \%$ & Sangat kurang & Revisi \\
\hline
\end{tabular}

(Adaptasi dari Kuswandi dalam Kartini, 2011)

Secara kumulatif apabila hasil yang diperoleh mencapai kreteria di atas nilai $74 \%$ maka buku latihan/ praktik yang dikembangkan dianggap memiliki nilai validitas positif yang memadai dan dapat dinyatakan layak untuk digunakan (Kuswandi dalam Kartini, 2011).

Keterapan atau keefektifan buku praktik hasil pengembangan dapat diketahui dengan melakukan analisis data dari hasil pre-test dan post-test uji uji lapangan/kelas sesungguhnya. Dari data ini akan diketahui apakah produk hasil pengembangan, efektif atau tidak dalam meningkatkan prestasi belajar mahasiswa. Standar keberhasilan mahasiswa adalah apabilah mahasiswa dapat mencapai nilai 75 .

\section{HASIL PENELITIAN}

Penyusunan draf awal meliputi BLSAPD untuk pegangan dosen dan pedoman penggunaannya serta insturmen angket disiapkan. Selanjutnya melakukan proses pengumpulan data dengan observasi, konsultasi, FGD dan evaluasi BLSAPD melalui angket kelayakan dengan melibatkan ahli yaitu dua orang dosen akuntansi di Universitas Islam Riau.

Alasan validator dipilih untuk menguji, menanggapai serta memberikan masukan untuk isi materi buku adalah Drs Sukarni,. M.Si dan
Andre Eko Prabowo,. M.Pd adalah karena beliau mengajar mata kuliah Pengantar Akuntansi dan akuntansi keuangan. Diskusi dengan validator pertama selama 4 kali dan 3 kali untuk diskusi dengan validator kedua. Berbagai masukan dari validator tersebut di jadikan bahan untuk merefisi BLSAPD sebelum di uji cobakan di lapangan.

Masukan dari hasil diskusi dijadikan bahan revisi sebelum di ujicobakan dilapangan. Berdasarkan rata-rata penilaian ahli untuk BLSAPD untuk konstruksi ini, rata-rata jumlah keseluruhan yaitu 85,5 dipersentasekan menjadi $85,5 \%$ dan dinyatakan telah memenuhi kriteria kevalidan. Untuk Buku Pedoman penilaian ahli ditunjukan dengan jumlah rata-rata sebesar 89,6 yang dipersentasekan menadi $89,6 \%$ dan dinyatakan telah memenuhi kriteria kevalidan. Media dan desain Berdasarkan rata-rata penilaian ahli, jumlah persentase keseluruhan untuk media BLSAPD yaitu sebesar $72,83 \%$ dan dinyatakan telah memenuhi kriteria kevalidan. Sedangkan untuk Buku Pedoman dinyatakan dengan persentase sebesar $76 \%$ dan dinyatakan telah memenuhi kriteria kevalidan. Selain itu juga validoator mengisi catatan anget terbuka bila di perlukan. 
Dari hasil validasi ahli kemudian di ujicobakan di lapangan, yaitu uji perorangan, uji kolompok kecil dan uji lapangan. Proses uji perorangan menggunakan instrumen angket yang meliputi 4 aspek yaitu: (1) ketepatan pengetikan kata dalam kalimat, (2) ketepatan menggunakan huruf kapital, (3) ketepatan menggunakan huruf kecil, dan (4) ketepatan menggunakan tanda baca. Ke-empat aspek tersebut menggunakan kaedah penulisan bahasa yang baik dan benar. Persentase hasil uji perorangan BLSAPD adalah 97/112 $\mathrm{x} 100 \%=86,6 \%$.

Berdasarkan rekapitulasi hasil uji kelompok kecil terhadap BPSAPD, untuk aspek tampilan dinyatakan dalam persentase sebesar $78,06 \%$ sehingga buku ini dinyatakan sangat menarik bagi mahasiswa, untuk aspek bahasa dinyatakan dalam persentase sebesar $87,37 \%$ sehingga buku ini dinyatakan sangat mudah dipahami oleh mahasiswa, sedangkan untuk aspek isi materi dinyatakan dalam persentase sebesar $89,65 \%$ dan dinyatakan buku ini dalam kategori sangat jelas. Sehingga persentase hasil uji kelompok kecil secara keseluruhan dalah $78,06 \%+87,37 \%+89,65 \% / 3=84,66 \%$.

Dengan mengacu pada kriteria kelayakan produk pengembangan maka dapat dikatakan hasil uji kelompok kecil dikualifikasikan dalam kriteria valid dan praktis.

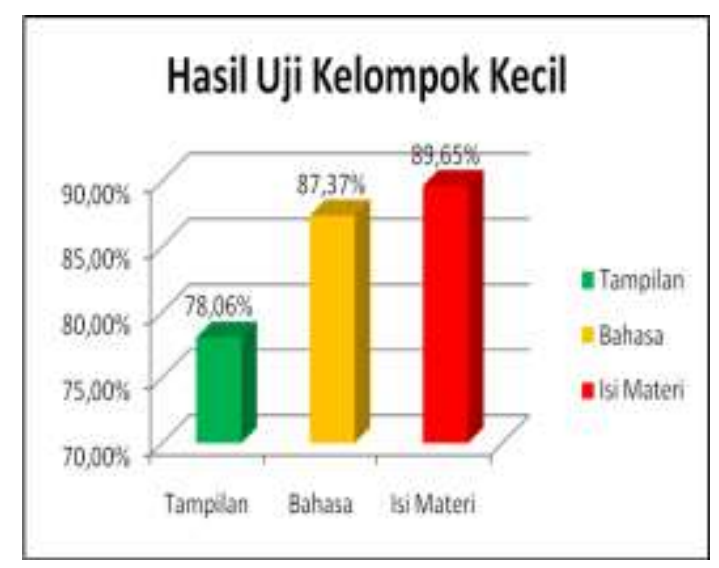

Setelah melakukan uji coba produk kelapangan dan pengamatan keterlaksanakan pembelajaran, peneliti didampingi melakukan kegiatan posttest. Hal ini dilakukan untuk mengetahui efektifitas BLSAPD dengan membandingkan hasil pre-test sebelum menggunakan BLSAPD dan hasil posttest setelah menggunakan BLSAPD. Dilihat dari hasil penilaian pre-test semua Mahamahasiswa mendapatkan kategori hasil belajar sangat rendah dengan rata-rata 72 dan hasil penilaian pos-test, 89. Artinya seluruh mahasiswa mendapatkan nilai diatas 75 . Hal ini menunjukan baha BLSAPD yang dikembangkan efektif untuk meningkatkan hasil belajar.

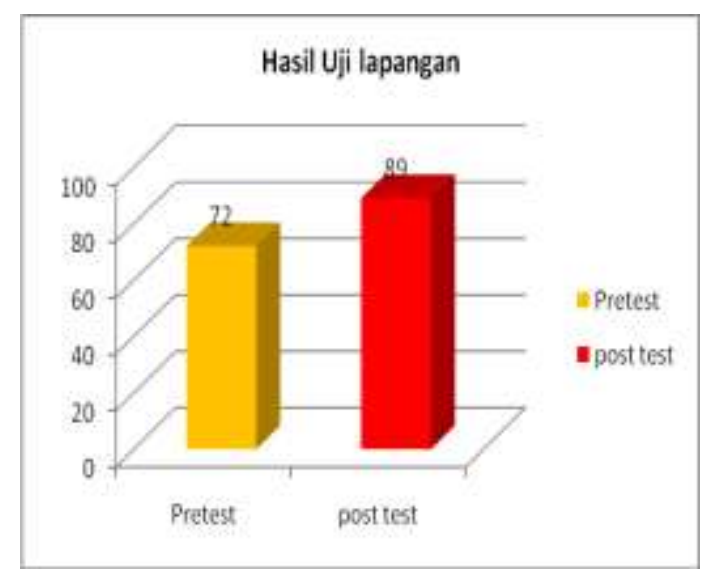

Cover dan Judul BLSAPD Untuk Mahasiswa dan Pegangan Dosen Pemberian judul pada Buku Praktikum Akuntansi Perusahaan Dagang (BUPRAK PD) bertujuan untuk membedakan BLSAPD untuk dikerjakan oleh mahasiswa dan BLSAPD untuk pegangan dosen. Hal ini penting dibedakan karena BLSAPD untuk mahasiswa berfungsi untuk melatih ketrampilan dan untuk dikerjakan mahasiswa sedangkan BLSAPD untuk pegangan dosen berfungsi untuk pegangan dosen dalam membimbing pada saat mahasiswa melakukan praktikum siklus akuntansi perusahaan dagang. 


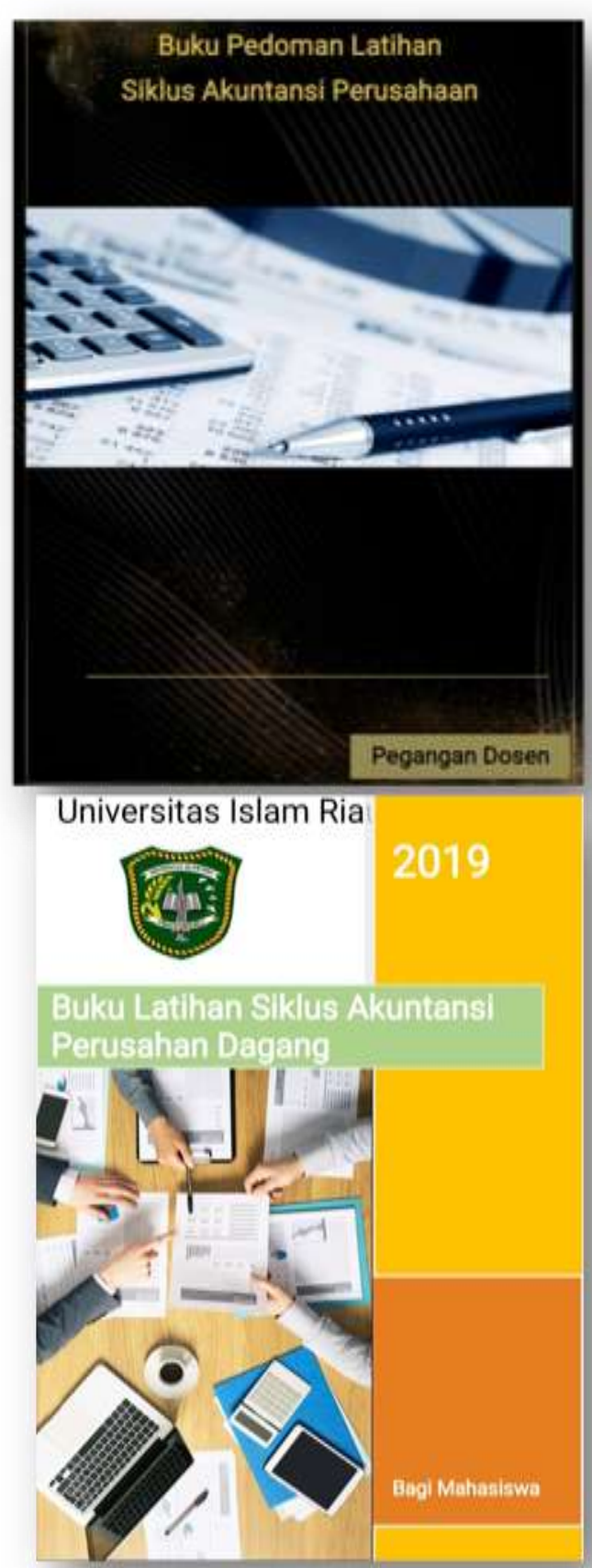

Tampilan cover untuk buku mahasiswa dibuat warna dengan gradasi cerah agar supaya dengan pewarnaan didasari keinginan pengembang untuk menciptakan kesan menarik bagi mahasiswa. Sedangkan untuk dosen dengan warna hitam coklat untuk kesan tajam dan dapat membedakan dengan buku mahasiswa. Berdasarkan saran ahli desain, warna cover boleh berbeda tetapi desain isi cover harus dibuat sama, maka pada cover BLSAPD dimasukkan gambar proses pembelajaran agar mencerminkan kegiatan praktikum hal ini dimaksudkan untuk memperjelas identitas bahan ajar berupa BLSAPD PD.

\section{PEMBAHASAN}

$\begin{array}{llr} & \text { Sesuai dengan kajian pustaka } \\ \text { yang } & \text { diperlukan } & \text { dalam }\end{array}$ mengembangkan bahan ajar berupa buku praktikum ini, font dalam buku praktikum ini menggunakan "Times New Roman" dan "Arial" dengan ukuran huruf mulai dari 12-16 disesuaikan dengan proporsional kebutuhan.Margin yang digunakan pada buku praktikum ini menggunakan model mirrored dengan batas atas $3 \mathrm{~cm}$, batas bawah $3 \mathrm{~cm}$, batas dalam $4 \mathrm{~cm}$ dan batas luar $3 \mathrm{~cm}$. Dengan margin ini siswa materi dan soal-soal praktikum lebih jelas terbaca dan mudah digunakan oleh siswa karena batas tepi tidak terlalu sempit.

Materi BLSAPD yang dimaksud adalah materi siklus akuntansi perusahaan dagang yang disajikan dalam sebuah buku latihan model praktikum, yang dimulai dari ilustrasi data transaksi, analisis bukti-bukti transaksi, jurnal khusus, jurnal umum, rekapitulasi jurnal khusus dan jurnal umum, buku besar, neraca saldo, jurnal penyesuaian, kertas kerja, sampai dengan menyusun laporan keuangan dan melakukan tahap penutupan periode akuntansi. Khusus mengenai adanya ilustrasi kegiatan perusahaan serta datadata perusahaan dan bukti-bukti transaksi secara real dalam BLSAPD dimaksudkan untuk memperkuat nuansa praktikum sesuai dengan kegiatan perusahaan dagang sebenarnya. 


\section{KESIMPULAN}

Berdasarkan rekapitulasi hasil uji kelompok kecil terhadap BPSAPD, untuk aspek tampilan dinyatakan dalam persentase sebesar $78,06 \%$ sehingga buku ini dinyatakan sangat menarik bagi mahasiswa, untuk aspek bahasa dinyatakan dalam persentase sebesar $87,37 \%$ sehingga buku ini dinyatakan sangat mudah dipahami oleh mahasiswa, sedangkan untuk aspek isi materi dinyatakan dalam persentase sebesar $89,65 \%$ dan dinyatakan buku ini dalam kategori sangat jelas. Sehingga persentase hasil uji kelompok kecil secara keseluruhan Adalah $84,66 \%$. Dengan mengacu pada kriteria kelayakan produk pengembangan maka dapat dikatakan hasil uji kelompok kecil dikualifikasikan dalam kriteria valid dan praktis.

Dilihat dari hasil penilaian pretest semua Mahamahasiswa mendapatkan kategori hasil belajar sangat rendah dengan rata-rata 72 dan hasil penilaian pos-test, 89. Artinya seluruh mahasiswa mendapatkan nilai diatas 75. Hal ini menunjukan baha BLSAPD yang dikembangkan efektif untuk meningkatkan hasil belajar.

\section{REFERENSI}

Ardhana, I W.,Willis, V. 1989. Reading in Instructional Development; Volume One. Jakarta: Departemen Pendidikan dan Kebudayaan, Direktorat Jendral Pendidikan Tinggi, P2LPTK.

Ardhana, I W.,Willis, V. 1989. Reading in Instructional Development; Volume Four. Jakarta: Departemen Pendidikan dan Kebudayaan, Direktorat Jendral Pendidikan Tinggi,

Degeng, I N.S. 1997. Asumsi dan landasanteoritik desain pembelajaran. Jurnal Teknologi
Pmbelajaran: Teori dan Penelitian, 5 (1): 3-12

Degeng, I N.S. 2001. Pengembangan Paket Pembelajaran. Malang LP3 Universitas Negeri Malang.

Dwi Yogo, W. 2010. Dimensi Teknologi Pembelajaran Pendidikan Jasmani dan Olah Raga.Malang: Wineka Media.

Gagne, R.M. Briggs, L.J \& Wager, W,W. 1992. Principles of Instructional Design. Orlando: Harcout Brace Jovanovich

Hobri. 2010. Metodologi Penelitian Pengembangan. Jember: Pena Salbila.

Heinich, R. Et.A;. 2002. Instructional Media and Technologies for Learning. New Jersey: Courier Kendallville

Hokanson, R \& Hoopper, S, 2004. Level Of teaching: A taxonomy for instructional design, Educational Technology, 44 (6): 14-22

Kartini T. 2011. Pengembangan Bahan Ajar Model Praktikum Akuntansi Koperasi Materi Pencatatan Buktibukti Transaksi Bagi Mahasiswa Program Studi Pendidikan Ekonomi FKIP Universitas Jember.Tesis tidak diterbitMalang. Universitas Negeri Malang.

Majid, M. 2011. Perencanaan Pembelajaran, Mengembang Standar Kompetensi Guru. Bandung: Remaja Rosdakarya.

Nur. M. 1996. Ketrampilan proses dan PBM pada Bidang Studi Teknologi dan Kejuaruan . Media Pendidikan No. 37 tahun XI.

Pannen, P. dan Purwanto. 2001, Penulisan Bahan Ajar. Jakarta: Pusat Antar Universitas, Pusat 
Pengembangan Aktivitas Akademik Universitas Terbuka.

Pujiati. 2006. Pengembangan Bahan Ajar Praktikum Pengantar Akuntansi Untuk Mahasiswa Jurusan Akuntansi. http://digilib.unila.ac.id/go.

Sugiono. 2010, Metode Penelitian Kuantitatif, Kualitatif dan $R \& D$. Bandung: Alfabeta.

Sugiarta. 2007. Metode Pembelajaran Praktikum Pengantar Akuntansi Menggunakan Microsoft Excel Pada Jurusan Akuntansi di Politehnik Bali.UNDIKSA: Jurnal Pendidikan dan Pengajaran, No.2 ThXXXXI April 2008.

Tennyson, R. D, 2002. Linking learning theories to instructional design Educational Technology, 42 (3): 51-55
Thiagarajan. S., Semmel. DS., \& Semmel, MI. 1974. Instructional Development for Training Techer of Exceptional Children. Minneapolis, Minnesota: Leardership Training Institute/special Education, Univercity of Minnesota.

Trianto. 2010. Mendesain Model Pembelajaran Inovatif-Progresif. Jakarta: Kencana Prenada Media Group.

Utomo, T dan Ruijter, K, 1991, Peningkatan dan Pengembangan Pendidikan, Jakarta, PT. Gramedia Pustaka Utama.

Zainuddin, M. 2005. Praktikum. Jakarta: Pusat Antar Universitas Untuk Peningkatan dan Pengembangan Aktivitas Instruksional Universitas Terbuka. 